\title{
Breakthrough modeling of furfural sorption behavior in a bagasse fly ash packed bed
}

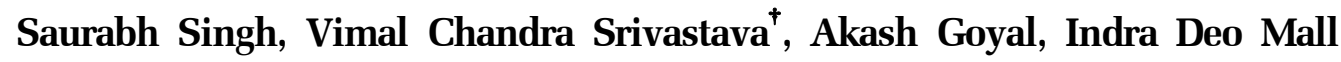 \\ Department of Chemical Engineering, Indian Institute of Technology Roorkee, Roorkee 247667, India
}

\begin{abstract}
Adsorptive breakthrough modelling is essential for design of a sorption packed bed. In this work, breakthrough modelling of the furfural uptake in bagasse fly ash (BFA) packed bed has been performed. Effect of various parameters like bed height $(\mathrm{Z}=15-60 \mathrm{~cm})$, flow rate $(\mathrm{Q}=0.02-0.04$ $\mathrm{L} / \mathrm{min})$ and initial furfural concentration $\left(\mathrm{C}_{0}=50-200 \mathrm{mg} / \mathrm{L}\right)$ on the breakthrough curve of furfural sorption in a BFA packed bed have been studied. Enhanced breakthrough performance was observed for the higher value of $Z$, and lower values of $C_{o}$ and $Q$. For $C_{o}=100 \mathrm{mg} / \mathrm{L}$, packed bed operated at $Q=0.03 \mathrm{~L} / \mathrm{min}$ and $\mathrm{Z}=60 \mathrm{~cm}$ was found to have lowest adsorbent utilization rate of $5.61 \mathrm{~g} / \mathrm{L}$ with highest breakthrough volume of $14.67 \mathrm{~L}$. Bed depth service time and Thomas models well represented the experimental data points under all experimental conditions. It can be concluded that BFA can be utilized efficiently in continuous system for the removal of furfural. Overall, more than $99 \%$ of furfural was adsorbed in BFA packed bed at experimental conditions.
\end{abstract}

Keywords: Bagasse fly ash, Breakthrough, Column study, Furfural removal, Sorption

\section{Introduction}

Various solvents are used in the petroleum refinery to meet the increasing demand of high quality fuels. Furfural is one of the popular solvents used in lube extraction unit in petroleum refineries. Besides this, usage or production of furfural is being practiced during various processes in numerous industries such as paper and pulp industry, pharmaceutical industry, petroleum refining, petrochemical and food industries [1, 2]. It finds its application as weed killer, flavoring agent, fungicide, and also as an intermediate in chemical reactions [3]. During these processes, furfural gets discharged into wastewater streams. Furfural is highly toxic in nature, and its presence in water makes it unusable. Further inebriating effects include ecstasy, giddiness, headache, queasiness, and eventual fainting and death due to breath loss. Prolonged skin exposure to furfural can cause skin allergy as well as an abnormal vulnerability to sunburn. Thus, to make it safe to use for domestic and industrial purpose, a thriving interest is seen nowadays for furfural removal from wastewater.

Various techniques such as biological (aerobic and anaerobic) treatment [4, 5], photo-oxidation [6] and adsorption [1, 2, 7, 8] have been used for removal of furfural from water. The increasing interest to explore novel and low-cost adsorbent has turned our awareness towards the adsorption capacities of other adsorbents namely agricultural by-products and residues [9-13]. As per industries view point, fixed-bed adsorption in continuous phase is generally desired. Instead of working directly on expensive experiments in continuous columns, an initial selection of adsorbents is being carried out using sorption isotherms. In earlier studies, bagasse fly ash (BFA) and activated carbon were tested for furfural sorption in batch process [1, 2]. Optimum uptake of furfural by $\mathrm{BFA}$ was achieved at $\mathrm{pH} \approx 5,5$, and adsorbent dose $\approx 4 \mathrm{~g} / \mathrm{L}$. The equilibrium for the adsorbate between the aqueous phase and on the surface of adsorbent was essentially reached within $4 \mathrm{~h}$. The maximum equilibrium furfural uptake obtained from BFA and activated carbon commercial-grade (ACC) was $86.97 \mathrm{mg} / \mathrm{g}$ and $22.2 \mathrm{mg} / \mathrm{g}$, respectively. Thus, it is inferred from the results that BFA was four times efficient than ACC in terms of sorption uptake of furfural.

The work presented here aims to report the performance of BFA packed bed for furfural adsorptive removal from its aqueous solution. The effects of bed height (Z), flow rate (Q) and initial furfural concentration $\left(\mathrm{C}_{0}\right)$ on the breakthrough point are also presented. Results of studies on testing of various models to predict the breakthrough curves are also presented.
This is an Open Access article distributed under the terms of the Creative Commons Attribution Non-Commercial License (http://creativecommons.org/licenses/by-nc/3.0/) which permits unrestricted non-commercial use, distribution, and reproduction in any medium, provided the original work is properly cited.

Copyright (C) 2020 Korean Society of Environmental Engineers
Received November 19, 2018 Accepted February 13, 2019

${ }^{\dagger}$ Corresponding author

Email: vimalcsr@yahoo.co.in, vimalfch@iitr.ac.in

Tel: +91-1332-285889 Fax: +91-1332-276535, 273560

ORCID: 0000-0001-5321-7981 


\section{Materials and Methods}

\subsection{Adsorbent}

BFA, used as an adsorbent in the present study, was obtained from a nearby sugar mill. It was used as such without any kind of pre-treatment. Exhaustive physico-chemical traits of the BFA are already presented the literature [11-13]. The average particle size of BFA was $167.35 \mu \mathrm{m}$. Proximate analysis manifested the presence of $7.6 \%$ moisture, $17.4 \%$ volatile matter, $26.4 \%$ ash and $49.6 \%$ fixed carbon in BFA. Bulk density of BFA was determined as $133.3 \mathrm{~kg} / \mathrm{m}^{3}$. The d-spacing values provided by the XRD spectra of BFA reflected the presence of alumina $\left(\mathrm{Al}_{2} \mathrm{O}_{3}\right)$, silica $\left(\mathrm{SiO}_{2}\right), \mathrm{CaO}, \mathrm{CaSiO}_{3}$, and $\mathrm{Ca}_{8} \mathrm{Si}_{5} \mathrm{O}_{18}$. The pore surface area of BFA was found to be $171 \mathrm{~m}^{2} / \mathrm{g}$, whereas $\mathrm{BJH}$ adsorption/desorption surface area of pores was 54.2/49.9 $\mathrm{m}^{2} / \mathrm{g}$. The average pore diameter of BFA was found to be 23.9 $\AA$ whereas the $\mathrm{BJH}$ adsorption/desorption average pore diameter was $39.4 \AA / 33.9 \AA$.

\subsection{Adsorbate}

The concentration of furfural was determined by using UV-spectrophotometer (HACH, DR/5,000). Maximum absorbance for this was obtained at a wavelength $\left(\lambda_{\max }\right)$ of $277 \mathrm{~nm}$ and the same was used to plot a model graph to relate absorbance and furfural concentration in the solution. The graph showed linear limit up to maximum furfural concentration of $10 \mathrm{mg} / \mathrm{L}$. Therefore, for reliable determination of the furfural in samples, dilution was done using distilled/milliQ water, for the samples having a concentration higher than $10 \mathrm{mg} / \mathrm{L}$ of furfural so as to lower the concentration of furfural below $10 \mathrm{mg} / \mathrm{L} \mathrm{[1].}$

\subsection{Column Studies}

Schematic representation of experimental set up is given in Fig. 1. A thermostatic heating device was used in the chamber in which the column assembly was kept so as to control the temperature and maintained at $303 \pm 1 \mathrm{~K}$. A plexiglas column having inside diameter (D) of $2.54 \mathrm{~cm}$ and length $90 \mathrm{~cm}$ was used for the experimental studies. The feed port for the column was provided at the bottom center of the column. Glass beads of $0.2-0.3 \mathrm{~cm}$ diameter were used to fill the lower portion of the column up to a height of $1.5 \mathrm{~cm}$. This was done to distribute the solution uniformly across the whole cross section of the column. Varying heights $(Z=15,30,45$ and $60 \mathrm{~cm})$ were chosen from the bottom to pack BFA in the column. Aqueous solution of furfural was pumped (upward flow) to bed using a peristaltic pump (Miclins PP20). The $C_{o}$ and $Q$ were varied in the range of $50-200 \mathrm{mg} / \mathrm{L}$ and 0.02-0.04 L/min, respectively. $\mathrm{pH}$ of the furfural solution in all experiments was 5.5 .

To achieve $100 \%$ wettability of packing inside the bed, an upward flow was adopted in the study presented. If done otherwise, it necessitated the use of specifically modelled distributors of liquid such that complete distribution of liquid is achieved inside bed [14]. Often, the holdup decreases as the liquid flow rate falls and the disturbance it causes in distribution of liquid poses great threat to the process efficacy $[15,16]$.

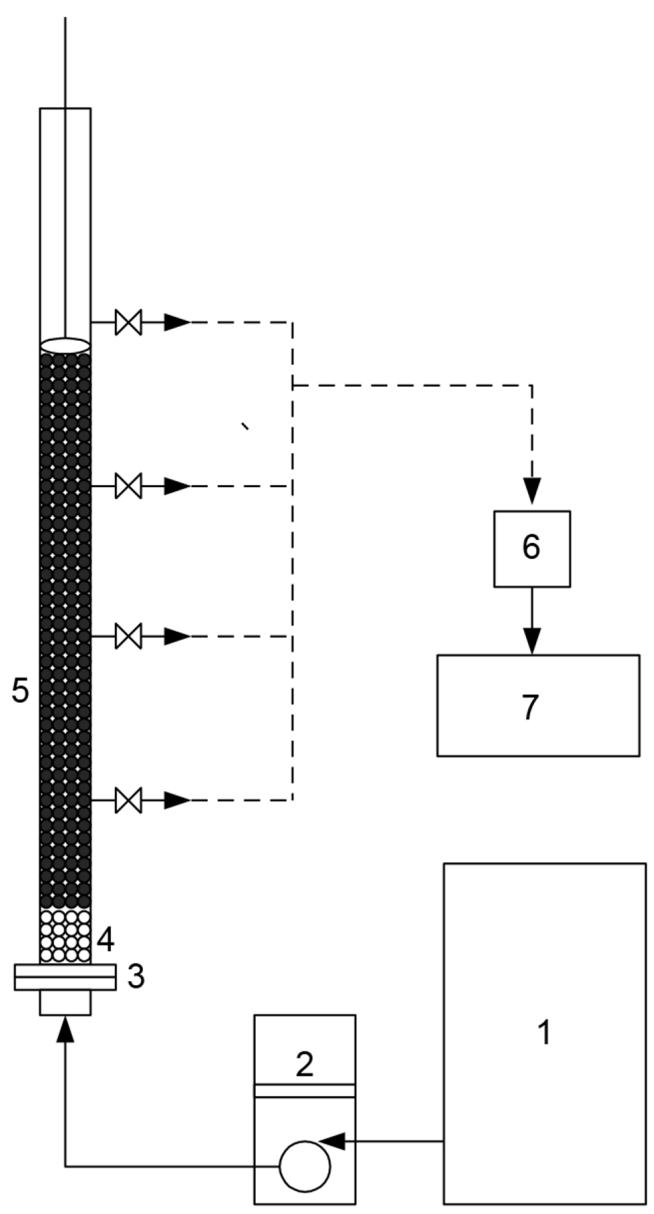

Fig. 1. Schematic diagram of experimental set up. (1) Reservoir tank with aqueous solution of furfural, (2) peristaltic pump, (3) supporting flange, (4) glass beads, (5) column, (6) filter media, (7) effluent storage.

\subsection{Theory: Behavior of Packed-bed Sorption Columns}

A typical experimental breakthrough curve is shown in Fig. 2(a). It was found that the furfural adsorbed on BFA was initially rapid such that the bulk solution released from the bed was having zero furfural in it. But the BFA started to satiate gradually as the furfural containing feed is fed for further time, and as a result, the amount of furfural in the bulk solution at outlet started to increase until the bed fully gets satiated. During actual operation, process is suspended as the amount of furfural in outlet solution increases up to a specified limit, known as breakthrough concentration, after which it is not suggested to proceed with the process. In the present study, the operation is continued till the bed reaches its satiation point. During estimation of typical variables of the system, breakthrough amount of furfural $\mathrm{C}_{\mathrm{BP}}\left(10 \%\right.$ of $\left.\mathrm{C}_{\mathrm{o}}\right)$ was set, and the time corresponding to this concentration was considered as breakthrough time $\left(\mathrm{t}_{\mathrm{BP}}\right)$.

The idea of the mass transfer zone (MTZ) was initially introduced in fixed bed columns' operation to understand the evolution patterns of the various parameters and to plan an efficient model 

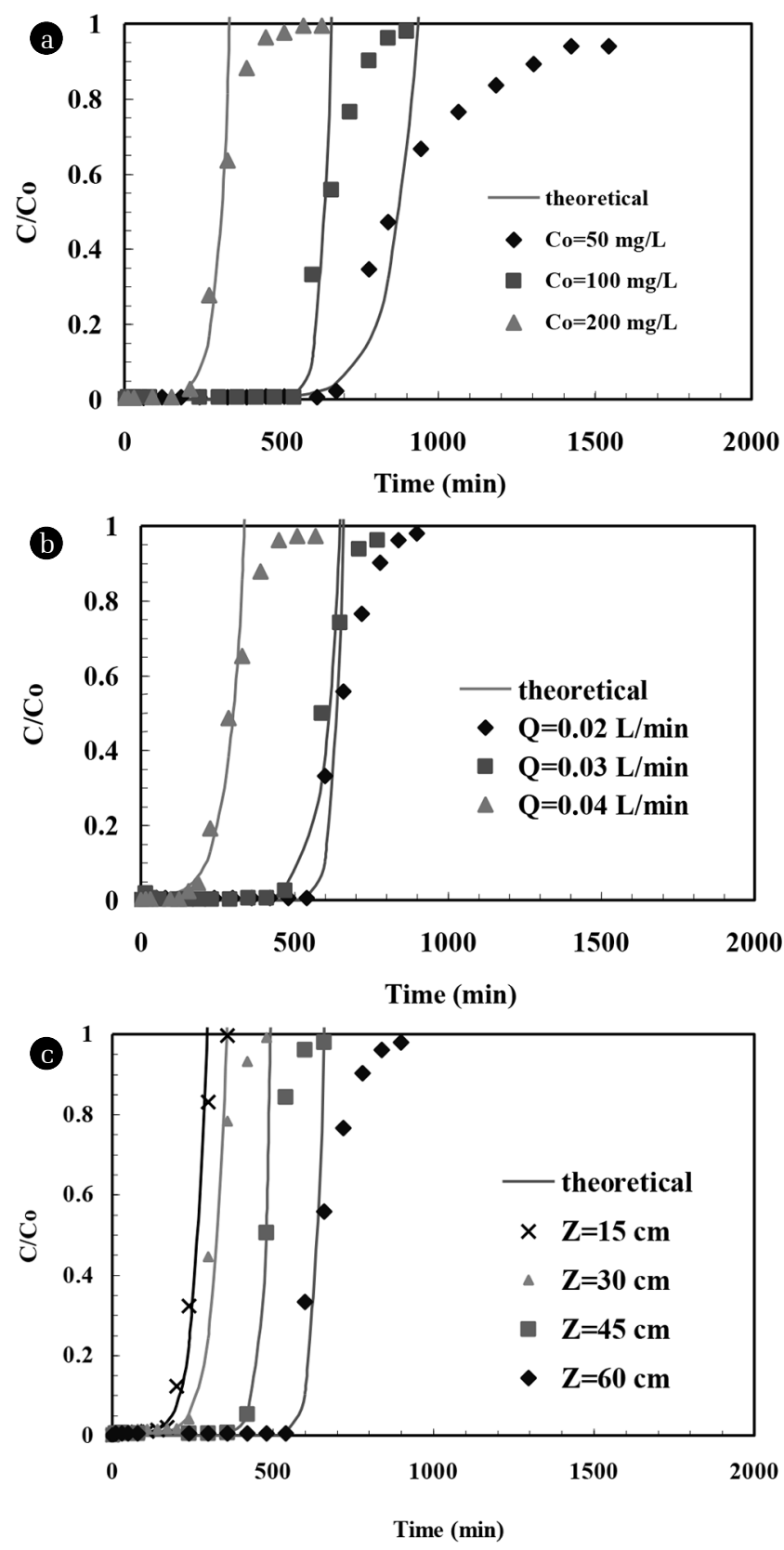

Fig. 2. Comparison of experimental and theoretical breakthrough curves for furfural sorption on BFA packed bed using the Bohart Adams model. Experimental values are shown by data points, and model predictions are represented by lines. (a) At varied $\mathrm{C}_{0}: \mathrm{Q}=0.02$ L/min, $Z=60 \mathrm{~cm}$. (b) At varied Q: $C_{0}=100 \mathrm{mg} / \mathrm{L}, Z=60 \mathrm{~cm}$. (c) At varied $\mathrm{Z}$ : $\mathrm{C}_{\mathrm{o}}=100 \mathrm{mg} / \mathrm{L}, \mathrm{Q}=0.02 \mathrm{~L} / \mathrm{min}$.

for better performance during sorption in a fixed bed column $[17,18]$. Significant sorption at any adsorbate inside the bed occurs in this MTZ [19]. Fractional capacity (F), the height of MTZ $\left(\mathrm{H}_{\mathrm{Z}}\right)$ and the speed of the MTZ along the bed height $\left(\mathrm{U}_{\mathrm{Z}}\right)$ determine the characteristics of the MTZ. They help us understand the way the adsorption process inside the bed advances. Various parameters of system can be expressed directly or indirectly using these parameters that control the overall sorption inside the bed. F is the term obtained when the proportional amount of adsorbent actually involved in sorption is divided by the total amount of adsorbent utilized for MTZ. In other words, it can be stated as the ratio of actual amount of adsorbate removed from the solution to the ideal extent of adsorbate removal by the adsorbent within the MTZ [17-19]. F is given as:

$F=\frac{A_{Z}}{A_{m x}}=\frac{\int_{V_{B P}}^{V_{E}}\left(C_{o}-C\right) d V}{C_{o}\left(V_{E}-V_{B P}\right)}=\frac{\int_{t_{B P}}^{t_{E}}\left(1-\left(C / C_{o}\right)\right) d t}{\left(t_{E}-t_{B P}\right)}$

where, $V_{E}$ is the bulk amount of effluent treated at the point of exhaustion time $\left(\mathrm{t}_{\mathrm{E}}\right)$ with immediate concentration $\left(\mathrm{C}_{\mathrm{E}}\right)$ equivalent to $90 \%$ of the amount in effluent $\left(\mathrm{C}_{\mathrm{o}}\right)$ at the start of process. Based on the fashion in which the bed is operating, this amount in effluent in selected randomly while keeping the process as economized as possible. $V_{B P}$ is the bulk amount of effluent treated at point of breakthrough time $\left(\mathrm{t}_{\mathrm{BP}}\right)$ with immediate concentration $\left(\mathrm{C}_{\mathrm{BP}}\right)$ which is lower than $10 \%$ of the amount present at the start of the process.

$H_{Z}$ is the area where practically all sorption takes place. It plays a significant role in evaluating the removal rate of adsorbate by the BFA, and guides regarding the diffusion resistances present during the process. The lower the resistance offered by the system, more the kinetics of uptake of adsorbate paces and shorter is the height of MTZ at any given instant. Thus, it proves to be a significant variable in figuratively estimating the overall kinetics of the uptake during the process. $\mathrm{H}_{\mathrm{Z}}$ is formulated as:

$$
H_{Z}=\frac{Z\left(t_{E}-t_{B P}\right)}{t_{B P}+F\left(t_{E}-t_{B P}\right)}
$$

$U_{Z}$ is basically used to evaluate the behavior of sorption in a fixed bed with continuous flow when a state of equilibrium is reached. It is basically an output function corresponding to the adsorbent's uptake potential, and thus, allows estimating the bed saturation rate. Being directly proportional to $\mathrm{H}_{\mathrm{Z}}$, it shows that as the $\mathrm{H}_{\mathrm{Z}}$ decreases, uptake rate of adsorbate increases, and the fixed bed satiates at a much faster rate [17-19]. $U_{Z}$ is given as:

$$
U_{Z}=\frac{H_{Z}}{t_{Z}}=\frac{Z}{t_{B P}+F\left(t_{E}-t_{B P}\right)}
$$

In order to find the efficacy of overall bed, we need to find number of unit transfer equivalents $\left(\mathrm{N}_{\mathrm{Z}}\right)$ [17]. It is given as:

$$
N_{Z}=\frac{H_{B P}}{H_{Z}}=\frac{t_{B P}+F\left(t_{E}-t_{B P}\right)}{\left(t_{E}-t_{B P}\right)}
$$

For a rapid uptake of adsorbate by adsorbent, lesser is $\mathrm{H}_{\mathrm{Z}}$ and higher is $\mathrm{N}_{\mathrm{Z}}$. Other than this, during a dynamic uptake process, larger values of $\mathrm{N}_{\mathrm{Z}}$ is avoided in order to avoid the rapid satiation of bed. 


\section{Results and Discussion}

\subsection{Effect of Initial Furfural Concentration}

The influence of $\mathrm{C}_{o}$ on breakthrough curves is shown by data points in Fig. 2(a) and the results are tabulated in Table 1. It is evident from the figure that $t_{0.1}$ decreased with an increase in the $\mathrm{C}_{0}$. At lower $\mathrm{C}_{0}$, curves were sparser and breakthrough occurred sluggishly. As the value of $\mathrm{C}_{\mathrm{o}}$ increased, the slope of breakthrough increased [20]. These results establish that any alteration in concentration gradient also alters the bed usage rate and the breakthrough time [21]. This occurs because large number of sorption sites gets occupied with an increase in $\mathrm{C}_{o}$. As the value of $\mathrm{C}_{0}$ increases, mass transfer driving force is seen to over- power the resistance offered by solution [22, 23]. This phenomenon helps the bed to increase its fractional capacity $(F)$. Also, along with the increase in furfural loading rate, which further causes the shortening of the sorption zone length $\left(\mathrm{H}_{\mathrm{Z}}\right)$ due to the increase in kinetics of process $[17,24]$. As $\mathrm{N}_{\mathrm{Z}}$ varies inversely to $\mathrm{H}_{\mathrm{Z}}$, a rise in its value is seen on the onset of increase in $\mathrm{C}_{0}$. Also, due to rapid satiation of sorption sites, $U_{Z}$ is seen to increase progressively with the increase in $\mathrm{C}_{0}[18,25]$.

The effect of $\mathrm{C}_{\mathrm{o}}$ on $\mathrm{F}, \mathrm{H}_{\mathrm{Z}}, \mathrm{U}_{\mathrm{Z}}$ and $\mathrm{N}_{\mathrm{Z}}$ is shown in Fig. 3(a) and (b). The value of $F$ (as per expectation) can be seen increasing from the graph as $C_{0}$ increases, until a maximum capacity limit of 0.435 for $C_{o}(=100 \mathrm{mg} / \mathrm{L})$ is achieved. After this, $C_{o}$ doesn't affect much on $F$ as the bed has already reached its maximum fractional capacity due to increase in $\mathrm{C}_{0}$ keeping every other parame-

Table 1. BFA Packed Bed Performance for Furfural Sorption

\begin{tabular}{|c|c|c|c|c|c|c|c|}
\hline $\mathrm{C}_{0}(\mathrm{mg} / \mathrm{L})$ & $\mathrm{Q}$ (L/min) & $\mathrm{Z}(\mathrm{cm})$ & EBCT (min) & $t_{\mathrm{BP}}(\mathrm{min})$ & $\mathrm{V}_{\mathrm{BP}}(\mathrm{L})$ & $\mathbf{N}_{\mathrm{BP}}$ & $U_{r}(\mathrm{~g} / \mathrm{L})$ \\
\hline 100 & 0.02 & 15 & 3.80 & 193.35 & 3.87 & 50.86 & 5.32 \\
\hline 100 & 0.02 & 30 & 7.60 & 248.80 & 4.98 & 32.72 & 8.27 \\
\hline 100 & 0.02 & 45 & 11.40 & 426.31 & 8.53 & 37.38 & 7.24 \\
\hline 100 & 0.02 & 60 & 15.21 & 557.30 & 11.16 & 36.65 & 7.38 \\
\hline 50 & 0.02 & 60 & 15.21 & 700.10 & 14.01 & 46.04 & 5.88 \\
\hline 100 & 0.02 & 60 & 15.21 & 557.30 & 11.15 & 36.65 & 7.38 \\
\hline 200 & 0.02 & 60 & 15.21 & 227.61 & 4.55 & 14.97 & 18.07 \\
\hline 100 & 0.02 & 60 & 15.21 & 557.30 & 11.15 & 36.65 & 7.38 \\
\hline 100 & 0.03 & 60 & 10.14 & 488.70 & 14.67 & 48.21 & 5.61 \\
\hline 100 & 0.04 & 60 & 7.61 & 200.16 & 8.01 & 26.33 & 10.28 \\
\hline
\end{tabular}
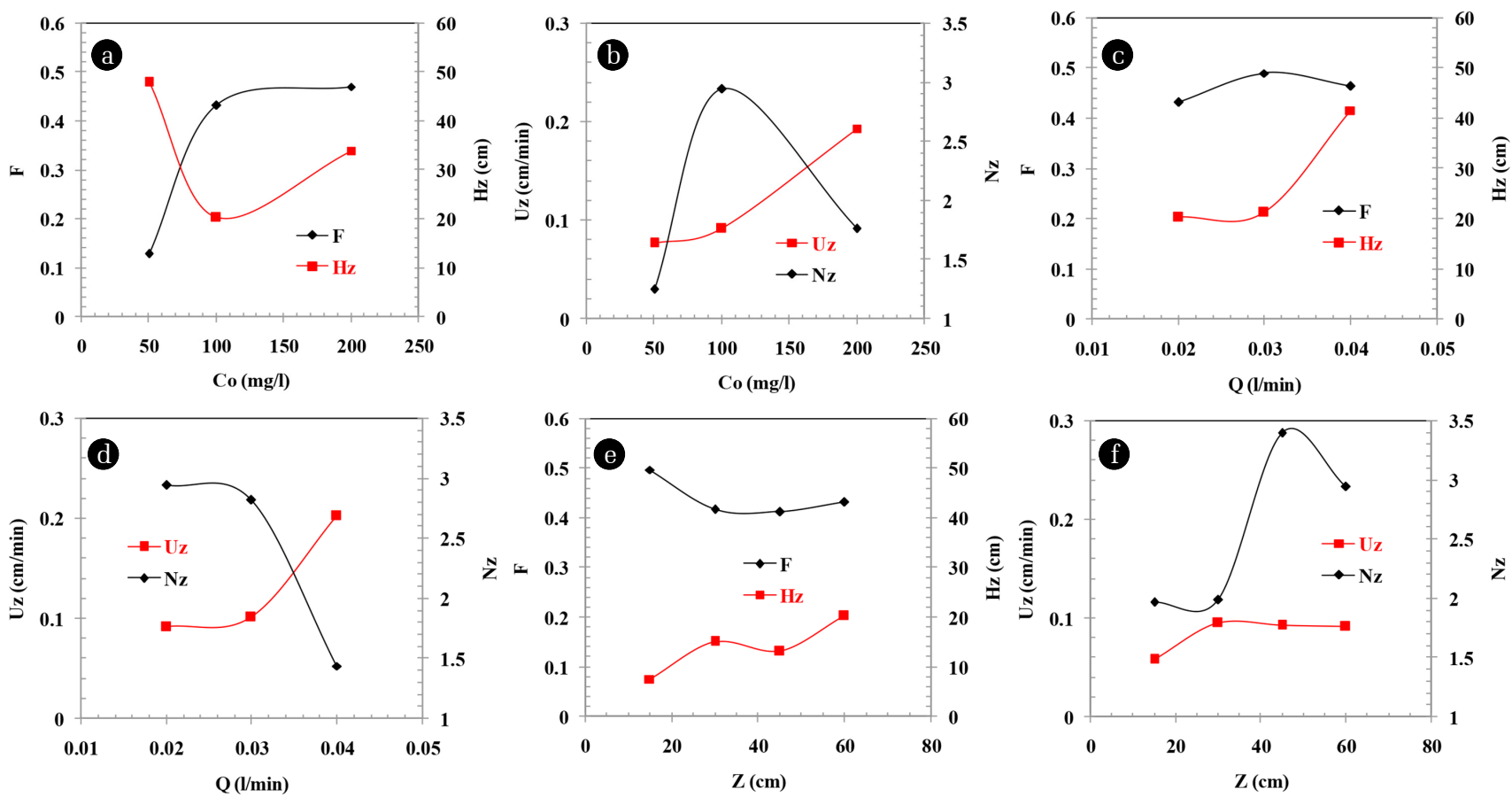

Fig. 3. The effect of initial furfural concentration $\left(C_{0}\right)$, flow rate $(Q)$ and bed height $(Z)$ on fractional capacity $(F)$, the height of mass transfer zone, MTZ $(\mathrm{Hz})$ and the rate of the movement of the MTZ $\left(\mathrm{U}_{\mathrm{Z}}\right)$, and number of mass transfer units $\left(\mathrm{N}_{\mathrm{z}}\right)$. 
ters constant. In accordance to the increasing $F, \mathrm{H}_{Z}$ can be seen decreasing to the point when $\mathrm{C}_{\mathrm{o}}$ reaches $100 \mathrm{mg} / \mathrm{L}$ making $\mathrm{H}_{Z}$ minimum at $20 \mathrm{~cm}$. Further this point, $\mathrm{H}_{\mathrm{Z}}$ again starts to increase as the bed reaches its limit of sorption capacity for the MTZ at any given instant. $\mathrm{N}_{\mathrm{Z}}$ rises to a maximum value of 3 at $\mathrm{C}_{0}$ (= $100 \mathrm{mg} / \mathrm{L})$ and further decreases as we increase $\mathrm{C}_{\mathrm{o}}$. A fashion of rise and decline $\mathrm{N}_{\mathrm{Z}}$ is due to the decrease of MTZ height during the first phase when $\mathrm{C}_{0}$ varies from $50-100 \mathrm{mg} / \mathrm{L}$ and then, increase in MTZ height after further increasing $C_{0}$, respectively [19, 26]. Also, $U_{Z}$ is increasing as we move from $(50-200) \mathrm{mg} / \mathrm{L}$. $U_{Z}$ is basically related directly with the satiation of column and increasing $\mathrm{C}_{0}$ ensured a rapid sorption.

\subsection{Effect of Flow Rate}

The breakthrough curves obtained for three Q $(=0.02,0.03$ and $0.04 \mathrm{~L} / \mathrm{min})$ at constant $\mathrm{Z}(=60 \mathrm{~cm})$ and $\mathrm{C}_{\mathrm{o}}(=100 \mathrm{mg} / \mathrm{L})$ were investigated. The experimental breakthrough times deduced from Fig. 2(b) are shown in Table 1 . The value of $t_{0.1}$ decreased as the value of $\mathrm{Q}$ increased. Inclusive of this, decreasing $\mathrm{Q}$ also resulted in the widening of breakthrough curve, which resulted in further increase in the difference between the breakthrough time and the saturation time. As anticipated, steeper curves with short mass transfer zone are seen due to reduction in breakthrough and exhaustion times, whenever there is a rise in $\mathrm{Q}$ [26-28].

The effect of $\mathrm{Q}$ on $\mathrm{F}, \mathrm{H}_{\mathrm{Z}}, \mathrm{U}_{\mathrm{Z}}$ and $\mathrm{N}_{\mathrm{Z}}$ is shown in Fig. 3(c) and (d). At lower Q (0.02 and $0.03 \mathrm{~L} / \mathrm{min})$, resistance for transfer of furfural from solution to adsorbent is less, thus, the removal of adsorbate is faster. Therefore, $\mathrm{H}_{\mathrm{Z}}$ and $\mathrm{U}_{\mathrm{Z}}$ are less at lower $\mathrm{Q}$ (0.02 and $0.03 \mathrm{~L} / \mathrm{min}$ ) as compared to at higher $\mathrm{Q}(0.04 \mathrm{~L} / \mathrm{min})$. At lower Q $(0.02$ and $0.03 \mathrm{~L} / \mathrm{min})$, shorter $\mathrm{H}_{\mathrm{Z}}$ increases the value of $\mathrm{N}_{\mathrm{Z}}$, therefore, the exhaustion of bed is better (i.e., better occupation of sites). This leads to increase in F. At higher Q (0.04 L/min), very less time is available for the volume element of solution to contact with the fixed bed which is inadequate to achieve equilibrium [19, 25]. This further leads to low sorption of adsorbate from the solution being fed at high $\mathrm{Q}$.

The value of $\mathrm{F}$ is higher at $\mathrm{Q}=0.03 \mathrm{~L} / \mathrm{min}$ as compared to that at $\mathrm{Q}=0.02 \mathrm{~L} / \mathrm{min}$. Generally, when $\mathrm{Q}$ is lowered, the liquid holdup gets decreased too and liquid maldistribution thus caused may show its impact on the efficacy of the bed [16]. At smaller liquid holdup, it is possible that some amount of the adsorbent may not get properly wet with the solution, and thus, don't participate in the sorption process and stay unutilized. Also, this improper circulation of solution may cause liquid to flow through a favorable channel in the bed and leave the rest of bed untouched [29]. The lower value of $\mathrm{F}$ at $\mathrm{Q}=0.02 \mathrm{~L} / \mathrm{min}$ may be attributed to channeling. As per the recent developments, it is seen that larger values of $\mathrm{Q}>0.03 \mathrm{~L} / \mathrm{min}$ are generally not preferred as it leads to rapid arrival of breakthrough and lesser sharp-edged.

\subsection{Effect of Bed Height}

The breakthrough curves for furfural sorption (shown in Fig. 2(c) by data points) were investigated at four different $\mathrm{Z}(=15,30$, 45 and $60 \mathrm{~cm}$ ) at a constant $\mathrm{Q}=0.02 \mathrm{~L} / \mathrm{min}$ and $\mathrm{C}_{o}=100 \mathrm{mg} / \mathrm{L}$. It can be seen that the $t_{B P}$ was lower for the lower values of $Z$, and increased with increase in $\mathrm{Z}$ due to the increase of the available surface area and binding sites for the furfural sorption. The breakthrough curves got flattened with an increase in Z. This is due to the widened mass transfer zone that cause breakthrough curve to be less steep. The breakthrough curves for the lowest Z showed a very little "tail" approaching saturation time because of the lesser amount of the BFA present inside the bed. As the value of $\mathrm{Z}$ is increased, a steep S shape breakthrough curve was seen [26, 28]. Due to intra-particle diffusion or non-idealities in flow at higher Z, breakthrough curves showed a broad tailing edge [30]. These results clearly reflect that the bed having greater value of $\mathrm{Z}$ was more difficult to completely exhaust as compared to bed having low value of $\mathrm{Z}[22,25,31,32]$.

\subsection{Empty Bed Contact Time and Adsorbent Usage Rate}

Empty bed contact time (EBCT) can be calculated using the following equation:

$$
E B C T=\frac{V_{C}}{Q}=\frac{A_{C} Z}{Q}
$$

The performance of an adsorbent packed bed is formulated in reference to the adsorbent usage rate $\left(U_{r}\right) . U_{r}$ is stated as the mass of adsorbent used per liter of solution treated [33].

$$
U_{r}=\frac{m_{C}}{V_{B P}}=\frac{V_{c} \rho}{V_{C} N_{B P}}=\frac{\rho}{N_{B P}}
$$

where, $V_{C}$ is the volume of the BFA in the packed-bed (L), $A_{C}$ is the cross-sectional area of the packed-bed $\left(\mathrm{cm}^{2}\right), m_{C}$ is the mass of the BFA in the packed-bed (g), $V_{B P}$ the volume of treated effluent discharged till breakthrough (L), $\rho$ is the apparent density of the BFA $\left(\mathrm{g} / \mathrm{cm}^{3}\right)$ and $N_{B P}$ is the bed volumes of the effluent to breakthrough.

Choosing $10 \%$ breakthrough point as the end point, the values of EBCT and $U_{r}$ were evaluated and the results are given in Table 1. As per the definitions, lower values of $U_{r}$ and higher values of $\mathrm{N}_{\mathrm{BP}}$ are desirable. Obtained results show that $\mathrm{U}_{\mathrm{r}}$ generally increased and $\mathrm{N}_{\mathrm{BP}}$ generally decreased with an increase in $\mathrm{Z}, \mathrm{C}_{\mathrm{o}}$ and Q. Adsorbent mass has a negative effect on $\mathrm{N}_{\mathrm{BP}}$ and $\mathrm{U}_{\mathrm{r}}$. Higher values of $U_{r}$ and lower values of $\mathrm{N}_{\mathrm{BP}}$ were found at higher $\mathrm{Z}$. In spite of more binding sites available for sorption at higher $\mathrm{Z}$, not all of them were accessible to the furfural molecules. This was due to operational problems such as axial dispersion, channeling and bed compaction [34, 35]. This behavior has been reported earlier as well [36]. For $\mathrm{C}_{\mathrm{o}}$ as variable parameter, it is obvious that higher amount of furfural at higher $\mathrm{C}_{\mathrm{o}}$ will exhaust the bed early and $U_{\mathrm{r}}$ values would be higher which is undesirable. The amount of furfural molecules that enter the packed-bed increase the adsorption rate, causing higher values of $U_{r}$ and lower values of $\mathrm{N}_{\mathrm{BP}}$. Similar results were found by other authors as well [36, 37]. With an increase in $\mathrm{Q}$ from $0.02 \mathrm{~L} / \mathrm{min}$ to $0.03 \mathrm{~L} / \mathrm{min}$, positive effect (lower values of $U_{r}$ and higher values of $\mathrm{N}_{\mathrm{BP}}$ ) was observed. This was because of the decrease in film which offers mass transfer resistance around BFA particles [38]. However, further increase in $\mathrm{Q}$ to $0.04 \mathrm{~L} / \mathrm{min}$ decreased the performance (higher values of $\mathrm{U}_{\mathrm{r}}$ and lower values of $\mathrm{N}_{\mathrm{BP}}$ ) because of the inadequate residence 
time of the liquid phase in the packed-bed and availability of less time for furfural diffusion into the pores of the BFA [39, 40].

\subsection{Breakthrough Modeling}

During sorption operation in any packed bed, the main motive is to minimize the concentration in the effluent so that it does not go beyond critical limited of $\mathrm{C}_{\mathrm{BP}}$. During start, when the BFA is fresh and unsaturated, the actual effluent concentration does not exceed $\mathrm{C}_{\mathrm{BP}}$. As pumping of furfural solution is continued through the bed, the BFA uptake capacity starts to decrease and the effluent concentration increasingly approaches $\mathrm{C}_{\mathrm{BP}}$ i.e., the breakthrough point is attained. Different models are utilized by researchers in the literature for the estimation of breakthrough time. In this current work, bed depth service time (BDST) and Thomas models have been utilized for the estimation of the breakthrough time for furfural sorption onto BFA. Srivastava et al. [33] have shared in the literature the theory linked to these models.

Earlier work on the BDST model was done by Bohart and Adams [41], who formulated a correlation between $\mathrm{Z}$ and breakthrough time $\left(t_{\mathrm{BP}}\right)$. The description of initial phase of breakthrough curve is done generally using Bohart-Adams model [42]. As for the rest of the typical operational variables of the system, they can be evaluated from the plot of $\mathrm{C} / \mathrm{C}_{\mathrm{o}}$ against $\mathrm{t}$ for a set value of $\mathrm{Z}$ and Q [25, 41]. Hutchins [43] linearized this model as follows:

$$
t=\frac{N_{o}}{C_{o} U} Z-\frac{1}{k_{B} C_{o}} \ln \left(\frac{C_{o}}{C}-1\right)
$$

where, $C$ is the desired concentration of the furfural at time $t$ (mg/L), $k_{B}$ is the furfural sorption rate constant in the packed-bed (L/min $\mathrm{mg}$ ), $N_{o}$ is the adsorptive or saturation capacity of the BFA packed-bed $(\mathrm{mg} / \mathrm{L})$ and $U$ is the linear flow velocity of the feed $(\mathrm{cm} / \mathrm{min})$. Here, the slope of the plot $\left(\mathrm{N}_{\mathrm{o}} / \mathrm{C}_{0} \mathrm{U}\right)$ represents the adsorptive capacity of the system whereas the intercept (I) gives the value of rate constant $\mathrm{k}_{\mathrm{B}}$ as per the following given equation [42]:

$$
I=\frac{-1}{k_{B} C_{o}} \ln \left(\frac{C_{o}}{C}-1\right)
$$

At halfway in breakthrough curve, when $\mathrm{C}_{\mathrm{o}} / \mathrm{C}=2$ and $\mathrm{t}=$ $t_{0.5}$, and therefore, the equation reduces as:

$$
t_{0.5}=\frac{N_{o}}{C_{o} U} Z
$$

Thus, it infers a linear plot of time passing through the origin for $t_{0.5}$ against $\mathrm{Z}$ at $50 \%$ breakthrough, allowing $\mathrm{N}_{\mathrm{o}}$ to be calculated. The dynamic behavior of the packed-bed sorption was predicted by BDST model given above and Thomas model given in subsequent paragraph. Coefficient of determination $\left(\mathrm{R}^{2}\right)$ and Marquardt's percent standard deviation (MPSD) were used to estimate the error between the experimental and calculated values of $\mathrm{C} / \mathrm{C}_{0}[33]$ :

$$
M P S D=100 \sqrt{\frac{1}{N-P} \sum_{i=1}^{n}\left(\frac{\left(C / C_{0}\right)_{\exp }-\left(C / C_{0}\right)_{c a l}}{\left(C / C_{0}\right)_{\exp }}\right)_{i}^{2}}
$$

where, $N$ represents the number of data points and $P$ represents the number of parameters. The deviation between the experimental and calculated $t_{\mathrm{BP}}$ was calculated by using the following equation:

$$
\varepsilon=100\left(\frac{t_{B P, \exp }-t_{B P, \text { cal }}}{t_{B P, \exp }}\right)(11)
$$

The plot of $t_{0.5}$ and $t_{0.1}$ obtained at constant $\mathrm{Q}=0.02 \mathrm{~L} / \mathrm{min}$ and $\mathrm{C}_{\mathrm{o}}=100 \mathrm{mg} / \mathrm{L}$ are against four different $\mathrm{Z}(15,30,45$ and $60 \mathrm{~cm}$ ) is shown in Fig. 4. It gives a linear relationship. As stated, $50 \%$ breakthrough curve between $\mathrm{t}$ and $\mathrm{Z}$ should have been a linear plot passing through the origin, however, despite being linear it does not pass through origin. This indicates that a much more complex mechanism is involved in furfural uptake using BFA and that more than one rate-limiting step exists during the process [44]. No and $\mathrm{k}$ as calculated from the slope and the intercept of $t_{0.1}$ versus $\mathrm{Z}$ plot are found to be $3,338 \mathrm{mg} / \mathrm{L}$ and 0.000562 $\mathrm{L} / \mathrm{mg}$ min, respectively. $\mathrm{N}_{\mathrm{o}}$ values showed deviation of $3.88 \%$ when compared with estimated using 10\% breakthrough and 50\% breakthrough plot. Fig. 2 shows the experimental and theoretical breakthrough curves predicted by BDST model at various experimental conditions. It shows a very good fit to the data up to $50 \%$ sorption of furfural. This suggests that the BDST model is valid for the relative concentration region up to 0.5 . The values of $\mathrm{N}_{o}$ and $\mathrm{k}_{\mathrm{B}}$ as calculated from Eq. (7) are tabulated in Table 2. It is seen that the value of $\mathrm{k}_{\mathrm{B}}$ generally increases with an increase in $\mathrm{Z}$ and decrease in $\mathrm{Q}$.

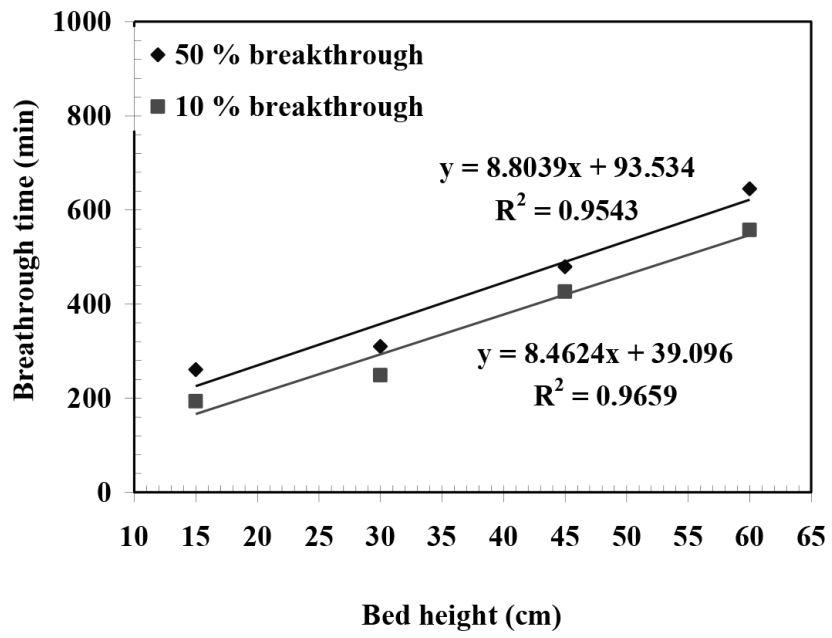

Fig. 4. BDST plot of breakthrough time versus bed height for furfural sorption onto BFA packed bed.

Thomas model [45] is based on the second order reaction kinetics. The linear form of the Thomas model is given as [18, 25, 46]:

$$
\ln \left(\frac{C_{o}}{C}-1\right)=\frac{k_{T} q_{o} m}{Q}-\frac{k_{T} C_{o}}{Q} V_{e f f}
$$

where, $k_{T}$ is the Thomas rate constant (L/min mg), $q_{o}$ the maximum sorption capacity of the BFAe (mg/g), $m_{C}$ is the mass of the BFA 
Table 2. Parameters Estimated Using Bohart-Adam Model

\begin{tabular}{|c|c|c|c|c|c|c|c|c|c|}
\hline $\mathrm{C}_{\mathrm{o}}(\mathrm{mg} / \mathrm{L})$ & $\mathbf{Q}(\mathrm{L} / \mathrm{min})$ & $\mathrm{Z}(\mathbf{c m})$ & 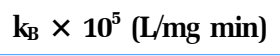 & $\mathrm{N}_{\mathrm{o}}(\mathrm{mg} / \mathrm{L})$ & $t_{B P, \exp }(\min )$ & $t_{\mathrm{BP}, \mathrm{cal}}(\mathrm{min})$ & $\varepsilon$ & $\mathbf{R}^{2}$ & MPSD \\
\hline 100 & 0.02 & 15 & 26.97 & 7,775 & 193 & 210 & 8.68 & 0.9501 & 60.75 \\
\hline 100 & 0.02 & 30 & 24.65 & 4,704 & 248 & 264 & 6.16 & 0.9419 & 71.09 \\
\hline 100 & 0.02 & 45 & 37.70 & 4,369 & 426 & 437 & 2.50 & 0.9813 & 80.12 \\
\hline 100 & 0.02 & 60 & 37.94 & 4,341 & 557 & 599 & 7.50 & 0.9133 & 92.92 \\
\hline 50 & 0.02 & 60 & 24.38 & 3,069 & 700 & 744 & 6.32 & 0.8883 & 436.43 \\
\hline 100 & 0.02 & 60 & 37.94 & 4,341 & 557 & 599 & 7.53 & 0.9133 & 429.62 \\
\hline 200 & 0.02 & 60 & 13.17 & 4,444 & 227 & 250 & 10.00 & 0.9647 & 326.99 \\
\hline 100 & 0.02 & 60 & 37.94 & 4,341 & 557 & 599 & 7.53 & 0.9133 & 438.67 \\
\hline 100 & 0.03 & 60 & 19.42 & 6,408 & 488 & 531 & 8.65 & 0.9748 & 377.64 \\
\hline 100 & 0.04 & 60 & 17.94 & 4,455 & 200 & 210 & 5.06 & 0.9531 & 570.54 \\
\hline
\end{tabular}
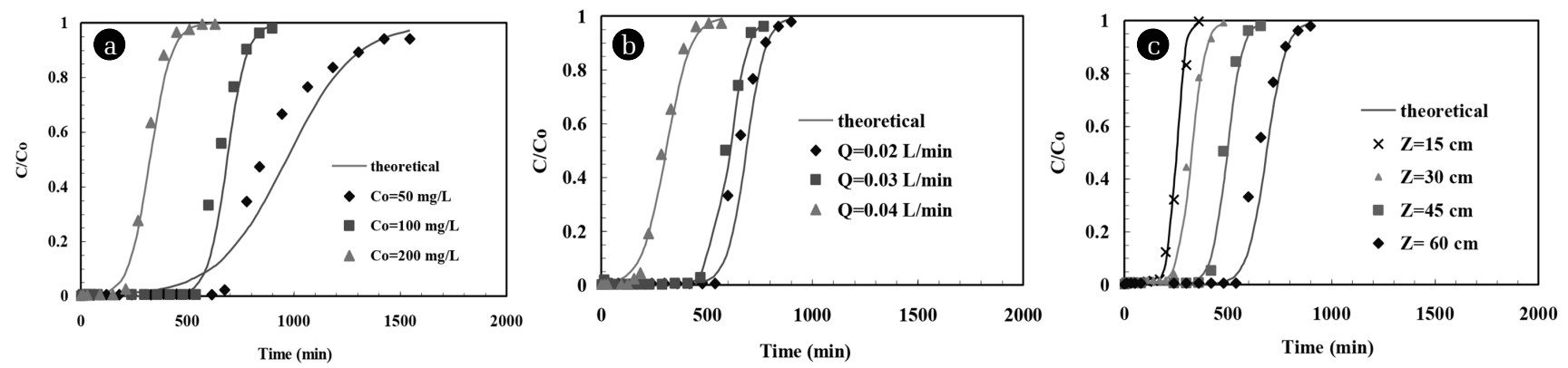

Fig. 5. Comparison of experimental and theoretical breakthrough curves for furfural sorption on BFA packed bed using the Thomas model. Experimental values are shown by data points, and model predictions are represented by lines (a) At varied $\mathrm{C}_{0}: \mathrm{Q}=0.02 \mathrm{~L} / \mathrm{min}, \mathrm{Z}=60 \mathrm{~cm}$. (b) At varied Q: $C_{0}=100 \mathrm{mg} / \mathrm{L}, Z=60 \mathrm{~cm}$. (c) At varied Z: $C_{o}=100 \mathrm{mg} / \mathrm{L}, Q=0.02 \mathrm{~L} / \mathrm{min}$.

Table 3. Parameters Estimated Using Thomas Model

\begin{tabular}{|c|c|c|c|c|c|c|c|c|c|}
\hline $\mathrm{C}_{0}(\mathrm{mg} / \mathrm{L})$ & $\mathrm{Q}$ (L/min) & $\mathrm{Z}(\mathbf{c m})$ & $\mathrm{k}_{\mathrm{T}} \times 10^{5}(\mathrm{~L} / \mathrm{mg} \mathrm{min})$ & $q_{o}(\mathrm{mg} / \mathrm{g})$ & $t_{B P, \exp }(\min )$ & $t_{\mathrm{BP}, \mathrm{cal}}(\mathrm{min})$ & $\varepsilon$ & $\mathbf{R}^{2}$ & MPSD \\
\hline 100 & 0.02 & 15 & 48.22 & 3.59 & 193 & 205 & 6.09 & 0.9892 & 69.45 \\
\hline 100 & 0.02 & 30 & 30.97 & 2.34 & 248 & 255 & 2.60 & 0.9895 & 68.56 \\
\hline 100 & 0.02 & 45 & 27.82 & 2.38 & 426 & 418 & 1.77 & 0.9721 & 94.85 \\
\hline 100 & 0.02 & 60 & 21.89 & 2.47 & 557 & 588 & 5.47 & 0.9370 & 152.35 \\
\hline 50 & 0.02 & 60 & 14.05 & 1.72 & 700 & 646 & 7.72 & 0.9063 & 684.01 \\
\hline 100 & 0.02 & 60 & 21.89 & 2.47 & 557 & 588 & 5.47 & 0.9370 & 427.13 \\
\hline 200 & 0.02 & 60 & 11.38 & 2.34 & 227 & 230 & 0.96 & 0.9801 & 359.89 \\
\hline 100 & 0.02 & 60 & 21.89 & 2.46 & 557 & 588 & 5.47 & 0.9370 & 436.13 \\
\hline 100 & 0.03 & 60 & 23.27 & 3.28 & 488 & 515 & 5.30 & 0.9871 & 356.57 \\
\hline 100 & 0.04 & 60 & 20.33 & 2.19 & 200 & 197 & 1.54 & -0.9856 & 680.92 \\
\hline
\end{tabular}

in the column (g), and $V_{\text {eff }}$ is the throughput volume (L) [47]. The $\mathrm{k}_{\mathrm{T}}$ and $\mathrm{q}_{\mathrm{o}}$ can be determined from the intercept and the slope of the plot of $\ln \left[\left(\mathrm{C}_{o} / \mathrm{C}\right)-1\right]$ against $\mathrm{t}$ at a given $\mathrm{Q}$. Thomas model was applied to the data at $\mathrm{C} / \mathrm{C}_{0}$ ratios higher than 0.08 and lower than 0.99 with respect to $\mathrm{Z}, \mathrm{C}_{\mathrm{o}}$ and $\mathrm{Q}$ [48-50]. $\mathrm{k}_{\mathrm{T}}$ and $\mathrm{q}_{\mathrm{o}}$ values are shown in Table 3. Values of $\mathrm{R}^{2}$ were found to be $>0.9063$. Sahu et al. [1] found that the sorption kinetics of furfural onto BFA was represented by second order kinetics. Therefore, Thomas model was expected to well-represent the breakthrough curves [26]. Fig. 5 shows the experimental and theoretical breakthrough curves obtained at different $\mathrm{Z}, \mathrm{C}_{\mathrm{o}}$ and $\mathrm{Q}$ for the Thomas model. Fig. 5 and the data in Table 3 indicate that the $t_{0.1}$ values as estimated using the Thomas model were very similar to those obtained from experimental results.

Comparison of the kinetic rate constants, $\mathrm{k}_{\mathrm{B}}$ and $\mathrm{k}_{\mathrm{T}}(\mathrm{L} / \mathrm{mg} \min )$, obtained by modeling the experimental breakthrough curves with 
the Bohart-Adams and Thomas models shows some difference in values among them, however, they were of the same order of magnitude in general. $\mathrm{N}_{\mathrm{o}}$ in Bohart-Adams model represents saturation capacity of the adsorbent bed whereas $q_{o}$ in the Thomas model represents the maximum adsorption capacity of the BFA. Values of $\mathrm{N}_{o}$ and $\mathrm{q}_{\mathrm{o}}$ generally decreased with an increase in $\mathrm{Z}$. This is because of inaccessibility of all active sites despite the increase in active sites at higher $\mathrm{Z}$ value which can be attributed to problems such as axial dispersion, channeling and bed compaction [34, 35]. An increase in the value of $\mathrm{N}_{o}$ and $\mathrm{q}_{\mathrm{o}}$ was observed with an increase in $\mathrm{C}_{o}$ and $\mathrm{Q}$ up to certain limit. Higher load of furfural in the BFA bed at higher $\mathrm{C}_{o}$ and $\mathrm{Q}$ increased the driving force which increased the $\mathrm{N}_{\mathrm{o}}$ and $\mathrm{q}_{\mathrm{o}}[51,52]$. Also, the reduction mass transfer resistance because of the decrease in the size of laminar boundary layer/film around BFA particles at higher $\mathrm{C}_{\mathrm{o}}$ and $\mathrm{Q}$ increased the $\mathrm{N}_{\mathrm{o}}$ and $\mathrm{q}_{\mathrm{o}}$ values [38]. The obtained breakthrough curves for furfural removal by BFA fitted better by Bohart-Adams model. This illustrates that the furfural and the functional groups on the surface of BFA interacted via hydrogen bonding, dipole-dipole and hydrophobic interactions among furfural and these interaction played significant role in the adsorption process [53]. Since, Thomas model is not able to better-predict the breakthrough curves than Adams-Bohart model. Hence, the external and internal diffusions seem to be the limiting steps during the sorption process [52].

\section{Conclusions}

Sorption of furfural from aqueous solution onto BFA was studied using packed column at $303 \mathrm{~K}$ in a continuous fashion. Improvement in bed performance was observed with an increase in $\mathrm{Z}$ and decrease in $\mathrm{Q}$ and $\mathrm{C}_{0}$. For $\mathrm{C}_{0}=100 \mathrm{mg} / \mathrm{L}$, packed bed operated at $Q=0.03 \mathrm{~L} / \mathrm{min}$ and $\mathrm{Z}=60 \mathrm{~cm}$ was found to have lowest adsorbent utilization rate $\left(\mathrm{U}_{\mathrm{r}}\right)$ of $5.61 \mathrm{~g} / \mathrm{L}$ with highest breakthrough volume $\left(\mathrm{V}_{\mathrm{BP}}\right)$ of $14.67 \mathrm{~L}$. Adam-Bohart model well predicted the breakthrough curve up to $50 \%$ breakthrough at all $\mathrm{Z}, \mathrm{C}_{0}$ and Q. Adsorptive capacity of BFA as calculated from $\mathrm{C} / \mathrm{C}_{0}$ BDST model for $10 \%$ breakthrough plot was $3,338 \mathrm{mg} / \mathrm{L}$. Thomas model was also applied at $\mathrm{C} / \mathrm{C}_{0}$ higher than 0.08 and lower than 0.99 for the prediction of breakthrough curves. Thomas model was found to be appropriate to explain the dynamic behavior of overall column or a section of the column in association to all $\mathrm{Z}, \mathrm{C}_{o}$ and $\mathrm{Q}$.

\section{Nomenclature}

$\mathrm{N}_{\mathrm{BP}}$ bed volumes to breakthrough

$\mathrm{N}_{\mathrm{Z}} \quad$ number of unit transfer equivalents

$\mathrm{P}$ number of parameters

Q volumetric flow rate $(\mathrm{L} / \mathrm{min})$

$\mathrm{q}_{\mathrm{o}} \quad$ maximum solid-phase concentration of the solute $(\mathrm{mg} / \mathrm{g})$

$\mathrm{t} \quad$ contact time (min)

$t_{\mathrm{BP}} \quad$ breakthrough time (min)

$\mathrm{t}_{0.1} \quad$ time for $10 \%$ adsorbate breakthrough (min)

$\mathrm{t}_{0.5} \quad$ time for $50 \%$ adsorbate breakthrough (min)

$t_{\mathrm{E}} \quad$ exhaustion time (min)

\section{References}

1. Sahu AK, Mall ID, Srivastava VC. Studies on the adsorption of furfural from aqueous solution onto low-cost bagasse fly ash. Chem. Eng. Commun. 2008;195:316-335.

2. Sahu AK, Mall ID, Srivastava VC. Adsorption of furfural from aqueous solution onto activated carbon: Kinetic, equilibrium and thermodynamic study. Sep. Sci. Technol. 2008;43:1239-1259.

3. Steyermark A. Kirk-Othmer encyclopedia of chemical technology. Vol. 14. 3rd ed. Microchemical Journal. New Jersey; John Wiley \& Sons, Inc; 1984.

4. Pitter P. Determination of biological degradability of organic substances. Water Res. 1976;10:231-235.

5. Rivard CJ, Grohmann K. Degradation of furfural (2-furaldehyde) to methane and carbon dioxide by anaerobic consortium. Appl. Biochem. Biotechnol. 1991;28:285-295.

6. Borghei SM, Hosseini SN. Comparison of furfural degradation by different photooxidation methods. Chem. Eng. J. 2008; 139:482-488.

7. Gupta P, Nanoti A, Garg MO, Goswami AN. The removal of furfural from water by adsorption with polymeric resins. Sep. Sci. Technol. 2001;36:2835-2844.

8. Lucas S, Cocero MJ, Zetzl C, Brunner G. Adsorption isotherms for ethylacetate and furfural on activated carbon from supercritical carbon dioxide. Fluid Phase Equilibria 2004;219:171-179.

9. Mall ID, Srivastava VC, Kumar GVA, Mishra IM. Characterization and utilization of mesoporous fertilizer plant waste carbon for adsorptive removal of dyes from aqueous solution. Colloids Surf. A: Physicochem. Eng. Asp 2006;278:175-187.

10. Mane V, Mall ID, Srivastava VC. Kinetic and equilibrium isotherm studies for the adsorptive removal of brilliant green dye from aqueous solution by rise husk ash. J. Environ. Manage. 2007;84:390-400.

11. Srivastava VC, Mall ID, Mishra IM. Treatment of pulp and paper mill wastewaters with poly aluminium chloride and bagasse fly ash. Colloids Surf. A: Physicochem. Eng. Asp 2005;260:17-28

12. Srivastava VC, Mall ID, Mishra IM. Modelling individual and competitive adsorption of cadmium(II) and zinc(II) metal ions from aqueous solution onto bagasse fly ash. Sep. Sci. Technol. 2006;41:2685-2710.

13. Srivastava VC, Mall ID, Mishra IM. Adsorption thermodynamics and isosteric heat of adsorption of toxic metal ions 
onto bagasse fly ash (BFA) and rice husk ash (RHA). Chem. Eng. J. 2007;132:267-278.

14. Treybal RE. Mass-transfer operations. 3rd ed. McGraw-Hill International Editions; 1981.

15. Inglezakis VJ, Hadjiandreou KJ, Loizidou MD, Grigoropoulou HP. Pretreatment of natural clinoptilolite in a laboratory-scale ion exchange packed bed. Water Res. 2001;35:2161-2166.

16. Milan Z, Sanchez E, Weiland P, et al. Ammonia removal from anaerobically treated piggery manure by ion exchange in columns packed with homoionic zeolite. Chem. Eng. J. 1997;66:65-71.

17. Namane A, Hellal A. The dynamic adsorption characteristics of phenol by granular activated carbon. J. Hazard. Mater. 2006;137:618-625.

18. Gilca E, Maicaneanu A, Ilea P. Kinetics analysis of zinc sorption in fixed bed column using a strongly basic anionic exchange resin. Water Sci. Technol. 2015;71:1646-1653.

19. Yazid H, Amour L, Terkmani A, Maachi R. Biosorption of lead from aqueous solution by biologically activated date pedicels: Batch and column study. Desalin. Water Treat. 2013;51:1690-1699.

20. Sulaymon AH, Yousif SA, Al-Faize MM. Competitive biosorption of lead, mercury, chromium and arsenic ions onto activated sludge in fixed bed adsorber. J. Taiwan Inst. Chem. Eng. 2014;45:325-337.

21. Goel J, Kadirvelu K, Rajagopal C, Garg VK. Removal of lead(II) by adsorption using treated granular activated carbon: Batch and column studies. J. Hazard. Mater. 2005;125:211-220.

22. Thanhmingliana, Lalhriatpuia C, Tiwari D, Lee SM. Efficient removal of $17 \beta$-estradiol using hybrid clay materials: Batch and column studies. Environ. Eng. Res. 2016;21:203-210.

23. Vera LM, Bermejo D, Uguña MF, Garcia N, Flores M, González E. Fixed bed column modeling of lead(II) and cadmium(II) ions biosorption on sugarcane bagasse. Environ. Eng. Res. 2018;24:31-37.

24. Han R, Ding D, Xu Y, et al. Use of rice husk for the adsorption of congo red from aqueous solution in column mode. Bioresour. Technol. 2002;99:2938-2946.

25. Gobi K, Mashitah MD, Vadivelu VM. Utilising waste activated sludge from a palm oil mill effluent treatment plant to remove methylene blue in continuous column studies. Int. J. Environ. Eng. 2012;4:253-268.

26. Sadaf S, Bhatti HN. Batch and fixed bed column studies for the removal of Indosol Yellow BG dye by peanut husk. J. Taiwan Inst. Chem. Eng. 2014;45:541-553.

27. Lodeiro P, Cordero B, Grille Z, Herrero R, Sde V. Physicochemical studies of cadmium(II) biosorption by the invasive alga in Europe. Sargassum muticum. Biotechnol. Bioeng. 2004;88:237-247.

28. Lee I, Park JA, Kang JK, et al. Batch and flow-through column studies for $\mathrm{Cr}(\mathrm{VI})$ sorption to activated carbon fiber. Environ. Eng. Res. 2014;19:157-163.

29. Inglezakis VJ, Lemonidou M, Grigoropoulou HP. Liquid holdup and dispersion in zeolite packed beds. Chem. Eng. Sci. 2001;56:5049-5057.

30. Cooney DO. Adsorption design for wastewater treatment. Boca Raton, FL: Lewis Publishers; 1999.
31. Netpradit S, Thiravetyan P, Towprayoon S. Evaluation of metal hydroxide sludge for reactive dye adsorption in a fixed bed column system. Water Res. 2004;38:71-78.

32. Zulfadhly Z, Mashitah MD, Bhatia S. Heavy metals removal in fixed bed column by macro fungus Pycnoporus sanguineus. Environ. Pollut. 2001;112:463-470.

33. Srivastava VC, Prasad B, Mishra IM, Mall ID, Swamy MM. Prediction of breakthrough curves for sorptive removal of phenol by bagasse fly ash packed bed. Ind. Eng. Chem. Res. 2008;47:1603-1613.

34. McCabe WL, Smith JC, Harriott P. Unit operations of chemical engineering. 5th ed. Singapore: McGraw-Hill International Editions; 1993.

35. de Franco MAE, de Carvalho CB, Bonetto MM, Soares RP, Feris LA. Removal of amoxicillin from water by adsorption onto activated carbon in batch process and fixed bed column: Kinetics, isotherms, experimental design and breakthrough curves modelling. J. Clean. Prod. 2017;161:947-956.

36. de Franco MAE, de Carvalho CB, Bonetto MM, Soares RP, Feris LA. Diclofenac removal from water by adsorption using activated carbon in batch mode and fixed-bed column: Isotherms, thermodynamic study and breakthrough curves modeling. J. Clean. Prod. 2018;181:145-154.

37. Sotelo JL, Ovejero G, Rodríguez A, Alvarez S, Galan J, García J. Competitive adsorption studies of caffeine and diclofenac aqueous solutions by activated carbon. Chem. Eng. J. 2014;240:443-453.

38. Mthombeni NH, Mbakop S, Ray SC, Leswifi T, Aoyi Ochieng, Onyango MS. Highly efficient removal of chromium(VI) through adsorption and reduction: A column dynamic study using magnetized natural zeolite polypyrrole composite. J. Environ. Chem. Eng. 2018;6:4008-4017.

39. Lin S, Song Z, Che G, et al. Adsorption behavior of metal-organic frameworks for methylene blue from aqueous solution. Micro. Meso. Mater. 2014;193:27-34.

40. Hayati B, Maleki A, Najafi F, et al. Heavy metal adsorption using PAMAM/CNT nanocomposite from aqueous solution in batch and continuous fixed bed systems. Chem. Eng. J. 2018:346;258-270.

41. Bohart G, Adams EQ. Some aspects of the behavior of charcoal with respect to chlorine. J. Am. Chem. Soc. 1920;42:523-544.

42. Hadi M, Samarghandi MR, McKay G. Simplified fixed bed design models for the adsorption of acid dyes on novel pine cone derived activated carbon. Water Air Soil Pollut. 2011;218 197-212.

43. Hutchins RA. New method simplifies design of activated-carbon system. Chem. Eng. 1973;80:133-138.

44. Sharma DC, Foster CF. Column studies into the adsorption of chromium(VI) using sphagnum moss peat. Bioresour. Technol. 1995;52:261-267.

45. Thomas HC. Heterogeneous ion exchange in a flowing system. J. Am. Chem. Soc. 1944;66:1664-1666.

46. Zeinali F, Ghoreyshi AA, Najafpour G. Removal of toluene and dichloromethane from aqueous phase by granular activated carbon (GAC). Chem. Eng. Commun. 2012;199:203-220.

47. Dorado AD, Gamisans X, Valderrama C, Sole M, Lao C. Cr(III) removal from aqueous solutions: A straightforward model ap- 
proaching of the adsorption in a fixed-bed column. J. Environ. Sci. Health A Toxic Hazard. Subst. Environ. Eng. 2014;49:179-186.

48. Aksu Z, Gonen F. Biosorption of phenol by immobilized activated sludge in a continuous packed bed: Prediction of breakthrough curves. Process Biochem. 2004;39:599-613.

49. Ghali AE, Baouabb MHV, Roudeslia MS. Preparation, characterization and application of a [copper(II)/ethylenediamine-cotton] complex for the removal of AB25 from aqueous solution in a laboratory scale column. Chem. Eng. J. 2011;174:18-26.

50. Singh S, Srivastava VC, Mall ID. Fixed-bed study for adsorptive removal of furfural by activated carbon. Colloids Surf. A: Physicochem. Eng. Asp. 2009;332:50-56.
51. Xu X, Gao B, Tan X, et al. Nitrate adsorption by stratified wheat straw resin in lab-scale columns. Chem. Eng. J. 2013;226:1-6.

52. Gouran-Orimi R, Mirzayi B, Nematollahzadeh A, Tardast A. Competitive adsorption of nitrate in fixed-bed column packed with bio-inspired polydopamine coated zeolite. J. Environ. Chem. Eng. 2018;6:2232-2240

53. Niasar HS, Sreejon Das, Xu C, Ray MB. Continuous column adsorption of naphthenic acids from synthetic and real oil sands process-affected water (OSPW) using carbon-based adsorbents. Chemosphere 2019;214:511-518. 